\title{
Subclinical Hypothyroidism and the Risk of Hypercholesterolemia
}

\author{
William J. Hueston, MD \\ William S. Pearson, MHA \\ Department of Family Medicine, Medical \\ University of South Carolina, Charleston, SC
}

\begin{abstract}
BACKGROUND Subclinical hypothyroidism, defined as a mild elevation in thyroidstimulating hormone (TSH) levels in patients with normal serum thyroxine levels, has been associated with elevationed levels in serum cholesterol in some sample populations. These studies, however, have included referred patients and large numbers of patients with previously treated hyperthyroidism. The aim of this study was to assess whether subclinical hypothyroidism is associated with abnormal lipid levels in a population-based sample.
\end{abstract}

\begin{abstract}
METHODS Data from adults older than 40 years who did not previously have a diagnosis of hypothyroidism or who were taking thyroid replacement medication were analyzed from the National Health and Nutritional Examination Survey (NHANES) III. Subclinical hypothyroidism was defined as a TSH value of 6.7 to $14.9 \mathrm{mU} / \mathrm{L}$ and normal thyroxine $(\mathrm{n}=215)$. Euthyroid control adults included participants with a TSH in a normal range between 0.36 and $6.7 \mathrm{mU} / \mathrm{L}(\mathrm{n}=8,013)$. Outcomes examined were serum cholesterol, low-density lipoprotein cholesterol, high-density lipoprotein cholesterol, and triglyceride levels in those who had subclinical hypothyroidism and in euthyroid controls.
\end{abstract}

RESULTS Persons meeting the criteria for subclinical hypothyroidism had higher mean cholesterol levels ( 226 vs $217 \mathrm{mg} / \mathrm{dL}, P=.003$ ) and rates of elevated cholesterol levels $(74.2 \%$ vs $63.9 \%, P=0.02)$ than the euthyroid control group, but there were no significant differences in low-density lipoprotein (LDL) or highdensity lipoprotein (HDL) levels. When adjusted for age, race, sex, and the use of lipid-lowering drugs, however, subclinical hypothyroidism was not related to elevations in cholesterol levels (adjusted odds ratio [OR] $=1.06,95 \%$ confidence interval [Cl], 0.57-1.97), LDL levels (adjusted OR $=0.89 ; 95 \% \mathrm{Cl}, 0.59-1.35$ ), or triglyceride levels (adjusted $\mathrm{OR}=1.83 ; 95 \% \mathrm{Cl}, 0.87-3.85$ ) or to a low HDL level (adjusted OR $=0.94 ; 95 \% \mathrm{Cl}, 0.36-2.48$ ).

CONCLUSIONS Subclinical hypothyroidism does not appear to be associated with abnormalities in serum cholesterol or triglyceride levels when adjusted for confounding variables in this population-based study.

Ann Fam Med 2004;2:351-355. DOI: 10.1370/afm.79.

\section{INTRODUCTION}

0 ubclinical hypothyroidism, also called mild hypothyroidism, is a term used for a condition in which there are small elevations in thyroid-stimulating hormone, yet normal circulating levels of thyroid hormones. This condition is more common in the elderly and is found twice as often in women as in men. ${ }^{1,2}$ While it is uncommon in younger persons, by the age of 65 years, the overall prevalence of the disorder is about $17 \%$ in women and $7 \%$ in men. ${ }^{3}$

Despite recognition of this condition and the observation that a small percentage of these patients advance to overt hypothyroidism each year, controversy continues over whether elderly individuals should be screened for subclinical hypothyroidism. ${ }^{4-6}$ Whereas the American Thyroid Association ${ }^{7}$ has endorsed screening for this disorder, others, such as the US Preventive Services 
Task Force, ${ }_{1}^{8}$ have advised against routine screening. In addition, although the American College of Physicians recognizes that screening women older than 50 years for hypothyroidism may have some value, they specifically note that the benefit of treating patients with subclinical hypothyroidism has not been evaluated. ${ }^{9}$

The decision about whether to screen patients for this disorder is clouded by inconsistent evidence of any benefit from early treatment. A few trials have found that persons with subclinical hypothyroidism who are given L-thyroxine experience some improvements in their energy level and feelings of well-being. ${ }^{10-12}$ These studies, however, have had few participants, enrolled patients with preexisting thyroid disease resulting from thyroid ablation, and included patients referred to specialists rather than the general population. It is not clear that these results can be generalized to individuals who would be identified solely through mass-screening efforts.

Another finding that has been used to argue for screening and treatment of subclinical hypothyroidism is the observation that thyroid replacement in patients with subclinical hypothyroidism can reduce abnormalities in cholesterol. ${ }^{3,4,13}$ Lipid abnormalities are reported to be more common in patients with overt hypothyroidism and are thought to contribute to the disproportionate increase in cardiovascular risk in these persons. ${ }^{14}$ Some studies of patients with subclinical hypothyroidism also have shown that patients have elevations in their cholesterol levels. ${ }^{15-17}$ There are few population-based studies that have compared lipid levels in patients who have subclinical hypothyroidism with lipid levels in euthyroid persons. The purpose of this study was to determine whether lipid abnormalities are more common in patients with subclinical hypothyroidism when compared lipid levels in euthyroid individuals using data from the Third National Health and Nutritional Examination Survey (NHANES III).

\section{METHODS}

NHANES III (1988-1994), which is a cross-sectional study of a nationally representative sample of noninstitutionalized US residents, was used for this study. The NHANES III is a federally sponsored survey that includes a detailed health interview, physical examination, and laboratory testing. To assure a sufficient number of minority participants for meaningful analyses, the NHANES III oversamples minority groups. When the data are adjusted for this oversampling using weighting factors, the results are designed to represent a population estimate for the entire US population.

From the NHANES III data set, the adult questionnaire, physical examination, and laboratory sections were merged using the unique sequence number for

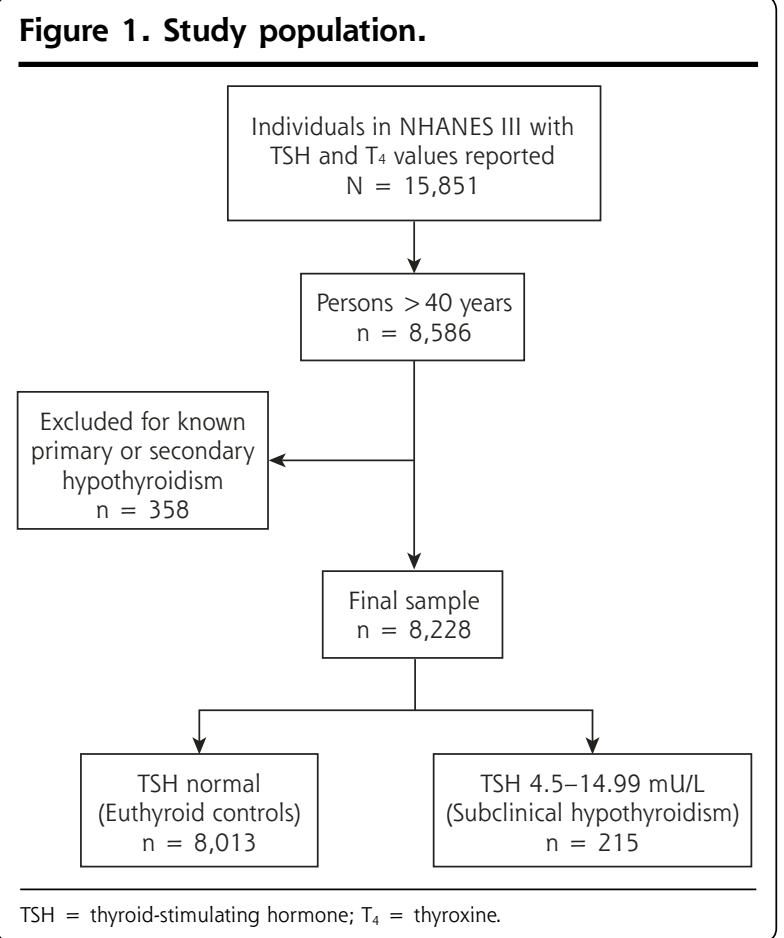

each respondent. The total number of respondents with reported thyroid-stimulating hormone (TSH) and thyroxine $\left(T_{4}\right)$ values was 15,851 . Because subclinical hypothyroidism is uncommon in younger persons, and the treatment of cholesterol abnormalities is less well defined in younger age-groups, we focused our analysis on persons 40 years of age and older. This approach produced a sample size of 8,586 (Figure 1). From this group, we attempted to exclude all respondents with known hypothyroidism by excluding respondents who were taking any medication that was prescribed for a diagnosis of primary or secondary hypothyroidism (ICD-9-CM codes 244.8 and 244.9), resulting in a final sample size of 8,228 .

We defined the subclinical hypothyroidism group as those with a TSH range of 6.70 to $14.99 \mathrm{mU} / \mathrm{L}$ and a $\mathrm{T}_{4}$ value greater than $4.5 \mu \mathrm{g} / \mathrm{dL}$. The euthyroid control group was classified as those with normal TSH values between $0.36 \mathrm{mU} / \mathrm{L}$ and $6.70 \mathrm{mU} / \mathrm{L}$.

Outcome measures were total cholesterol, high-density lipoprotein (HDL), low-density lipoprotein (LDL), and triglyceride levels. We looked at these measures as continuous variables and stratified each into bivariate categories representing high and low values. Respondents were considered to have a high total cholesterol level if the serum value was greater than $200 \mathrm{mg} / \mathrm{dL}$. Low HDL was defined as less than $35 \mathrm{mg} / \mathrm{dL}$. Elevation of LDL was defined as greater than $130 \mathrm{mg} / \mathrm{dL}$, while an elevation in triglycerides was defined as a value higher than $250 \mathrm{mg} / \mathrm{dL}$. These values were selected based on the recommendations 


\begin{tabular}{llcc|}
\hline \multicolumn{4}{c|}{ Table 1. Demographics of the Sample Population } \\
\hline \\
$\begin{array}{c}\text { Subclincal } \\
\text { Hypothyroidism } \\
\text { (n = 215) } \\
\text { No. (\%) }\end{array}$ & $\begin{array}{c}\text { Control } \\
\text { (n = 8.013) } \\
\text { No. (\%) }\end{array}$ & P Value \\
\hline Characteristic & $72(27.4)$ & $3,890(47.9)$ & $<.01$ \\
\hline Sex & $143(72.6)$ & $4,123(52.1)$ & \\
Male & & & $<.01$ \\
Female & $142(90.0)$ & $4,025(80.5)$ & \\
Race & $20(3.2)$ & $1,916(9.1)$ & \\
Non-Hispanic white & $43(3.0)$ & $1,751(3.5)$ & \\
Non-Hispanic black & $10(3.8)$ & $321(6.9)$ & \\
Mexican-American & & & \\
Other & $29(23.0)$ & $2,294(37.9)$ & \\
Age & $35(17.3)$ & $1,580(24.1)$ & \\
40-49 y & $45(23.4)$ & $1,865(20.4)$ & \\
$50-59$ y & $64(27.7)$ & $1,338(12.8)$ & \\
$60-69$ y & $42(8.6)$ & $936(4.8)$ & \\
$70-79$ y & &
\end{tabular}

Note: Percentages are weighted totals using SUDAAN to account for the complex sampling design of the NHANES III.

Table 2. Mean Lipid Values for Respondents with Subclinical Hypothyroidism and Controls

\begin{tabular}{lccc}
\hline & $\begin{array}{c}\text { Subclincal } \\
\text { Hypothyroidism } \\
\text { (n = 215) } \\
\text { Mean (SD) }\end{array}$ & $\begin{array}{c}\text { Control } \\
\text { (n= 8,013) } \\
\text { Mean (SD) }\end{array}$ & P Value \\
\hline Lipids & $226.0(44.2)$ & $217.1(43.7)$ & .003 \\
\hline Total cholesterol, mg/dL & $50.9(16.9)$ & $50.9(16.3)$ & .99 \\
$\begin{array}{c}\text { High-density lipoprotein, } \\
\text { mg/dL }\end{array}$ & $139.7(42.7)$ & $136.2(38.3)$ & .19 \\
$\begin{array}{c}\text { Low-density lipoprotein, } \\
\text { mg/dL }\end{array}$ & $178.1(99.7)$ & $157.5(114.7)$ & .01 \\
\begin{tabular}{l} 
Triglycerides, mg/dL \\
\hline
\end{tabular} & & & \\
\hline
\end{tabular}

Table 3. Comparison of Serum Lipid Profiles in Respondents with Subclinical Hypothyroidism and Controls

\begin{tabular}{lccc}
\hline & $\begin{array}{c}\text { Subclincal } \\
\text { Hypothyroidism } \\
\text { (n = 215) } \\
\text { No. (\%) }\end{array}$ & $\begin{array}{c}\text { Control } \\
\text { (n = 8,013) } \\
\text { No. (\%) }\end{array}$ & P Value \\
\hline Lipids & $160(74.2)$ & $5,134(63.9)$ & .02 \\
\hline $\begin{array}{l}\text { Total cholesterol } \\
>200 \mathrm{mg} / \mathrm{dL}\end{array}$ & $55(25.8)$ & $2,879(36.1)$ & \\
$\leq 200 \mathrm{mg} / \mathrm{dL}$ & & & .08 \\
$\begin{array}{l}\text { High-density lipoprotein } \\
<35 \mathrm{mg} / \mathrm{dL}\end{array}$ & $33(9.9)$ & $1,212(15.3)$ & \\
$\leq 35 \mathrm{mg} / \mathrm{dL}$ & $182(90.1)$ & $6,081(84.7)$ & \\
$\begin{array}{l}\text { Lwo-density lipoprotein } \\
>130 \mathrm{mg} / \mathrm{dL}\end{array}$ & $62(25.7)$ & $1,892(23.9)$ & \\
$\leq 130 \mathrm{mg} / \mathrm{dL}$ & $153(74.3)$ & $6,121(76.2)$ & \\
Triglycerides * & & & .09 \\
$>250 \mathrm{mg} / \mathrm{dL}$ & $39(20.8)$ & $1,034(13.9)$ & \\
$\leq 250 \mathrm{mg} / \mathrm{dL}$ & $176(79.2)$ & $6,979(86.1)$ & \\
\hline
\end{tabular}

*Not all respondents had triglyceride determinations. Note: Percentages are weighted totals using SUDAAN to account for the complex sampling design of the NHANES III. of the National Institutes of Health Adult Treatment Panel III ${ }^{8}$ report, which was the prevailing recommendations when data for the NHANES III were collected.

All analyses were performed using SUDAAN software (SUDAAN, Research Triangle Park, Cary, NC) to account for the complex sampling design of the NHANES III. SUDAAN allows for population estimates to be calculated despite the complex sampling design of the NHANES. For these 2 groups, we computed descriptive statistics and made bivariate comparisons using chi-square analysis and Student's $t$ test. Logistic regression models were used to control for age, sex, and race.

\section{RESULTS}

Of the 8,228 respondents included in the study, $215(2.6 \%)$ were found to fit the criteria for subclinical hypothyroidism. The characteristics of the persons with subclinical hypothyroidism and euthyroid control group are displayed in Table 1 We found that subclinical hypothyroidism was more common in women and in non-Hispanic whites and with increased age.

When we looked at serum lipid values for the entire group, we found that persons with subclinical hypothyroidism were more likely to have elevations in their average cholesterol and triglyceride levels (Table 2). When we dichotomized these variables into high or low based on national guidelines, we found that persons with subclinical hypothyroidism were more likely to have elevated total cholesterol levels. No statistically significant differences between persons with subclinical hypothyroidism and euthyroid controls were found in the percentage of respondents with abnormal HDL levels, LDL levels, or in triglyceride levels (Table 3 ).

Because treatment of elevated cholesterol levels with medications is common, we considered the possibility that preexisting elevations in lipid levels in the subclinical hypothyroid respondents might have been reduced as a result of use of lipid-lowering drugs. To explore this possibility, we looked at whether respondents in each group were taking cholesterol-lowering agents. We found that a greater percentage of respondents in the euthyroid control group (77.3\%) were taking cholesterol-lowering agents than were respondents in the subclinical hypothyroid group $(65.7 \%, P=.0004)$. Consequently, it was unlikely that the use of cholesterol-lowering therapy reduced the baseline lipid levels in 
subclinical hypothyroid respondents so that true differences were obscured. If anything, it was more likely that the euthyroid control group had higher baseline cholesterol and LDL values.

To examine whether other possible covariates could mask differences between the groups, we performed a logistic regression analysis using subclinical hypothyroidism and adjusting for any effects of sex, age, race, and the use of cholesterol-lowering medications on the risk of having an elevated total or LDL cholesterol levels. The analysis showed no effect of subclinical hypothyroidism on the frequency of abnormalities in total cholesterol, LDL, HDL, or triglycerides (Table 4).

The logistic regression analysis simply explored normal or abnormal lipid levels. Although there are recommended cutoffs for lipid abnormalities, the cardiovascular risk related to cholesterol abnormalities is linear in nature. To examine whether subclinical hypothyroidism is related to cholesterol values throughout the range of cholesterol, we performed a second analysis using linear regression and the same covariates noted above. Again, there was no statistically significant relationship between subclinical hypothyroidism and total cholesterol level $(P=85)$, LDL level $(P=.34)$, HDL $(P=.88)$, or triglyceride level $(P=.29)$.

\section{DISCUSSION}

In this population-based sample, compared with respondents who had normal TSH levels, respondents with mild elevations in their serum TSH and normal $\mathrm{T}_{4}$ levels were more likely to have elevations in cholesterol levels. After adjusting for demographic and other clinical variables, however, no significant relationship was found between cholesterol, HDL, or LDL levels and subclinical hypothyroidism. The only relationship that was significant after adjusting for potential confounding variables was an increase in the number of persons with high triglyceride levels and lower HDL levels in the subclinical hypothyroid group.

Hypercholesterolemia was common in both the subclinical hypothyroid group and the euthyroid control group. Nearly two thirds of this sample were taking cholesterol-lowering agents, which might account for the fairly good lipid levels observed in these respondents. The frequent use of cholesterol-lowering agents is common in this age-group, however. Another population-based study reported that in persons older than 65 years, $63 \%$ of participants were found to have a cholesterol level higher than $200 \mathrm{mg} / \mathrm{dL} .{ }^{19}$ Previous reports showing hypercholesterolemia to be common in persons with subclinical hypothyroidism may simply reflect that hypercholesterolemia is a common condition. This possibility is underscored by a recent
Table 4. Risk of Lipid Abnormality With Subclinical Hypothyroidism Adjusted for Potential Confounders

\begin{tabular}{lcc}
\hline Lipids & $\begin{array}{c}\text { Adjusted } \\
\text { Relative Risk* }\end{array}$ & $\begin{array}{c}\text { 95\% Confidence } \\
\text { Interval }\end{array}$ \\
\hline $\begin{array}{l}\text { Cholesterol > } 200 \mathrm{mg} / \mathrm{dL} \\
\text { Low-density lipoprotein } \\
>130 \mathrm{mg} / \mathrm{dL}\end{array}$ & 1.06 & $0.57-1.97$ \\
$\begin{array}{l}\text { High-density lipoprotein } \\
<35 \mathrm{mg} / \mathrm{dL}\end{array}$ & 0.89 & $0.59-1.35$ \\
$\begin{array}{l}\text { Triglyceride }>250 \mathrm{mg} / \mathrm{dL} \\
\text { * } \text { Adjusted with multivariate logistic regression for patient sex, race, age, and } \\
\text { whether patient was taking a cholesterol-lowering medication. }\end{array}$ & $0.36-2.48$ \\
\hline
\end{tabular}

report showing that while LDL levels were higher in overt hypothyroidism, there were no differences found between subclinical hypothyroid respondents and matched euthyroid controls. ${ }^{15}$

Our examination of thyroid function in NHANES III participants is similar to that of Hollowell et al, ${ }_{1}^{20}$ but there are several important differences. In their study, Hollowell and colleagues found that $4.3 \%$ of all persons had subclinical hypothyroidism. These researchers, however, did not exclude patients who had known hypothyroidism and were taking thyroid replacement medications, which constituted about $13 \%$ of their subclinical hypothyroidism group. Also, the cutoff value for a high TSH level in the Hollowell et al study was set at $4.5 \mathrm{mU} / \mathrm{L}$, a value lower than the value used in our study. Although the inclusion of patients with a TSH level between 4.5 and $6.7 \mathrm{mU} / \mathrm{L}$ increases the prevalence of subclinical hypothyroidism, these patients are least likely to have any clinical symptoms of hypothyroidism and have a lower risk of future progression compared with those who have higher TSH levels. Furthermore, there is no a priori reason why patients with TSH levels between 4.5 and $6.7 \mathrm{mU} / \mathrm{L}$ would have lipid levels that differ from those of patients with higher TSH levels, so the exclusion of these individuals should not alter our overall conclusions.

These findings have implications for recommendations on screening for subclinical hypothyroidism. Although one study has examined the cost utility of screening for subclinical hypothyroidism and found screening to be cost-effective, that study included the identification and treatment of lipid abnormalities as a benefit of screening. ${ }^{21}$ From these results, it would appear that screening for subclinical hypothyroidism simply to identify lipid abnormalities would be no more useful than screening for hyperlipidemia in general. Nor is there any evidence that treatment of hyperlipidemia in patients with subclinical hypothyroidism would be any different from treatment of hyperlipidemia in euthyroid patients. Consequently, analyses of the costeffectiveness of subclinical hypothyroidism screening 
that include a benefit from the treatment of lipid abnormalities may overestimate the value of screening.

The findings of this study must be interpreted within the limitations of the study design. In particular, the ability to determine whether treatment of previously elevated cholesterol levels is limited by the lack of information about current treatment regimens and how long the problem had been known to the patient. Thus, patients who had known about their cholesterol abnormalities for a few days were grouped in the same category as those who had been under treatment for several years. Although the effectiveness of therapy may be underestimated in this population, it is unlikely that the distribution in the time that patients knew about their hyperlipidemic condition or treatments would vary between the 2 groups.

Second, our assumption that the subclinical hypothyroid group is homogeneous might ignore the possibility that a subgroup of these persons might be at greater risk for hyperlipidemia. For example, patients with TSH values between 10 and $15 \mathrm{mU} / \mathrm{L}$ have been found to be at greater risk of advancing to overt hypothyroidism during the next few years. It is possible that this group or another subset also could be at higher risk for hypercholesterolemia or other sequelae related to overt hypothyroidism before the thyroid completely fails.

In addition, because of the cross-sectional nature of this analysis, it is difficult to ascribe causality to any associations we have found. Because we do not know whether thyroid test abnormalities preceded elevations in triglyceride levels, it cannot be definitely stated that one leads to the other. Further evaluation of this relationship with longitudinal data would be necessary to support a causal link.

Last, it is important to emphasize that this analysis focused solely on the benefits of finding subclinical hypothyroidism for the purposes of treating hyperlipidemias. Other beneficial effects of treatment, such as improvements in well-being, might be of sufficient value to patients to warrant screening. ${ }^{21}$ Further evaluation of patients from population-based screening programs who are found to have subclinical hypothyroidism rather than those referred for specialty management would be useful in determining the magnitude of these benefits in the general population.

To read or post commentaries in response to this article, see it online at http://www.annfammed.org/cgi/content/full/2/4/351.

Key words: hypothyroidism; mass screening; cholesterol

Submitted February 12, 2003; submitted, revised, June 23, 2003; accepted July 22, 2003.

Funding support: Support for this study was provided by grant 1 D12 HP 00023-01 from the Bureau of Health Profession, Health Resources Services Administration.

\section{References}

1. Sawin CT, Castelli WP, Hershman JM, McNamara P, Bacharach P. The aging thyroid: thyroid deficiency in the Framingham study. Arch Intern Med. 1985; 145:1386-1388.

2. Tunbridge WMG, Evered DC, Hall R, et al. The spectrum of thyroid disease in a community: the Whickham survey. Clin Endocrinol (Oxf). 1977;7:481-483.

3. Danese MD, Landenson PW, Meinert CL, Powe NR. Effect of thyroxine therapy on serum lipoproteins in patients with mild thyroid failure: a quantitative review of the literature. J Clin Endocrinol Metab. 2000;85:2993-3001.

4. Franklyn J. Subclinical hypothyroidism. Clin Endocrinol (Oxf). 1995;43:443-444.

5. Cooper DS. Subclinical thyroid disease: a clinician's perspective. Ann Intern Med. 1998;129:135-137.

6. American College of Physicians. Screening for thyroid disease. Ann Intern Med. 1998:129:141-143.

7. Ladenson PW, Singer PA, Ain KB, et al. American Thyroid Association guidelines for detection of thyroid dysfunction. Arch Intern Med. 2000; 160:1573-1575.

8. US Preventive Services Task Force. Guide to Clinical Preventive Services. 2nd ed. Alexandria, VA: International Medical Publishing; 1996.

9. Helfand M, Redfern CC. Clinical guideline, part 2. Screening for thyroid disease: an update. Ann Intern Med. 1998;129:144-158.

10. Cooper DS, Halpern R, Wood LC, Levin AA, Ridgway EC. L-thyroxine therapy in subclinical hypothyroidism: a double-blind, placebo-controlled trial. Ann Intern Med. 1984:101:18-24.

11. Nystrom E, Caidahl K, Fager G, Wikkelso C, Lundberg PA, Lindstedt G. A double-blind cross-over 12-month study of L-thyroxine treatment of women with 'subclinical' hypothyroidism. Clin Endocrinol (Oxf). 1988;29:63-75.

12. Jaescheke R, Guyatt G, Gerstein H, et al. Does treatment with L-thyroxine influence health status in middle-aged and older adults with subclinical hypothyroidism? J Gen Intern Med. 1996;11:744-749.

13. Meier C, Staud J, Roth CB, et al. TSH-controlled L-thyroxine therapy reduces cholesterol levels and clinical symptoms in subclinical hypothyroidism: a double blind, placebo-controlled trial (Basel Thyroid Study). J Clin Endocrinol Metab. 2001;86:4860-4866.

14. Morris MS, Bostom AG, Jacques PF, Selhub J, Rosenberg IH. Hyperhomocystinemia and hypercholesterolemia associated with hypothyroidism in the third US National Health and Nutrition Examination Study. Atherosclerosis. 2001;155:195-200.

15. Vierhapper H, Nardi A, Grosser P, Raber W, Gessl A. Low-density lipoprotein cholesterol in subclinical hypothyroidism. Thyroid. 2000; 10:981-984.

16. Canaris GJ, Manowitz NR, Mayor G, Ridgway EC. The Colorado thyroid disease prevalence study. Arch Intern Med. 2000; 150:526-534.

17. Pirich $C$, Mullner $M$, Sinzinger $H$. Prevalence and relevance of thyroid dysfunction in 1922 cholesterol screening participants. J Clin Epidemiol. 2000;53:623-629.

18. National Cholesterol Education Program Expert Panel. Summary of the second report of the National Cholesterol Education Panel (NCEP) Expert Panel on the Detection, Evaluation, and Treatment of High Blood Cholesterol in Adults (Adult Treatment Panel II). JAMA. 1993;269:3015-3023.

19. Manolio TA, Furberg CD, Wahl PW, et al. Eligibility for cholesterol referral in community-dwelling older adults. The Cardiovascular Health Study. Ann Intern Med. 1992;116:641-649.

20. Hollowell JG, Staehling NW, Flanders D, et al. Serum TSH, T4, and thyroid antibodies in the Unites States population (1988 to 1994): National Health and Nutrition Examination Survey (NHANES III). J Clin Endocrinol Metab. 2002;87:489-499.

21. Danese MD, Powe NR, Sawin CT, Ladenson PW. Screening for mild thyroid failure at the periodic health examination: a decision and cost-effectiveness analysis. JAMA. 1996;276:285-292. 